\title{
Physics teacher production: Patterns of institutional engagement and faculty theories
}

\author{
Rachel E. Scherr, ${ }^{1}$ Monica Plisch ${ }^{2}$, and Renee Michelle Goertzen ${ }^{2}$ \\ ${ }^{1}$ Seattle Pacific University, Department of Physics, \\ 3307 Third Avenue West, Seattle, WA, 98119 \\ ${ }^{2}$ American Physical Society, \\ One Physics Ellipse, College Park, MD, 20740
}

\begin{abstract}
The Physics Teacher Education Coalition (PhysTEC) seeks to better understand physics teacher education efforts taking place at member institutions, in order to better engage and support those institutions in educating greater numbers of well-prepared physics teachers. PhysTEC also seeks to understand faculty leaders' theories about barriers to increasing the number of physics teachers at their institution, in order to foster faculty leadership and support their efforts at institutional transformation. Institutions studied exhibit four broad patterns of institutional engagement with physics teacher education ("inactive," "track," "active," and "priority"). Faculty leaders' theories about the scarcity of future physics teachers refer to both structural and cultural barriers to educating more physics teachers.
\end{abstract}

keywords: physics teacher education

PACS: 01.40.Fk, 01.40.J-

\section{INTRODUCTION}

The Physics Teacher Education Coalition (PhysTEC) project was launched in 2001 by professional societies [1] concerned about the severe national shortage of qualified high school physics teachers. Since that time, the project has directly supported over 40 U.S. institutions to build model programs, and established a coalition of more than 300 institutions committed to improving the education of future physics teachers. PhysTEC-supported sites have collectively more than doubled the number of graduates per year from their physics teacher education programs. To put this in perspective, if all 760 institutions that grant physics degrees collectively doubled the number of well-prepared physics teachers per year, this would substantially address the national need for new physics teachers.

PhysTEC seeks to better understand physics teacher education activities at member institutions in order to better engage and support those institutions. PhysTEC also seeks to understand faculty theories about barriers to increasing the number of future physics teachers (i.e., students committed to completing a program of physics teacher education), in order to foster faculty leadership and support their efforts at institutional transformation.

In 2014, PhysTEC conducted an interview study to investigate patterns of institutional engagement with physics teacher education and faculty theories about the scarcity of future physics teachers. Results indicate that institutions exhibit four broad patterns of institutional engagement with physics teacher education ("inactive," "track," "active," and "priority"). Faculty leaders' theories about barriers to increasing the number of future physics teachers refer to both structural and cultural factors.

\section{THEORY}

Eckel \& Kezar [2] characterize institutional transformation in terms of structural changes on the one hand, and attitudinal and cultural changes on the other. Structural changes are readily documentable and quantifiable, such as changes in course offerings, curriculum, policies, budgets, and institutional structures. Attitudinal and cultural changes comprise changes in beliefs and assumptions regarding what an institution should be doing and how it should be doing it, reflected in changed interactions among personnel and departments, language indicating new priorities and relationships, and abandonment of old arguments. Below (Sec. IV), we describe patterns of institutional engagement with physics teacher education, mostly in terms of institutional structures. In what follows (Sec. V), we characterize faculty theories about low numbers of future physics teachers in terms of both structural and attitudinal and cultural barriers.

Identification of these barriers is a critical first step in fostering institutional changes needed to improve physics teacher education. Successful change strategies must take into account existing barriers or attempt to move them [3]. Moreover, efforts to improve physics teacher education 
programs must align with faculty beliefs about physics teacher education or seek to change them [3].

\section{METHODS}

Study participants were all representatives of PhysTEC "member institutions," institutions that self-identify as having physics teacher education as a priority. Out of over 300 PhysTEC member institutions [4], PhysTEC randomly issued 100 invitations to participate in the study. PhysTEC supported sites were not invited to participate. Invitations were issued to the individual on record as the faculty leader of physics teacher education efforts at that institution. Of these, 27 faculty leaders scheduled interviews. Almost all interviewees were physics faculty. Interviews were 15-30 minutes long, guided by the following protocol:

"As you know, the United States has a severe, long-term shortage of qualified physics teachers. PhysTEC is seeking to understand what it would take to resolve this shortage, i.e., for institutions to produce many more qualified physics teachers. Your institution, and you in particular, already have a commitment to physics teacher education.

- Please describe what is already going on with physics teacher education at your institution.

- How many physics teachers have you produced in the last five years?

- What has your institution tried to do to increase production of physics teachers?

- How many personnel are involved in physics teacher education? What is the total average FTE of personnel dedicated to physics teacher education?

- What funding supports physics teacher education? What is the total average amount per year?

- What challenges have you faced in producing physics teachers? In particular, what institutional barriers have you faced?

- What do you want to do to produce more physics teachers? What could PhysTEC do for you?

- What else would you like to tell PhysTEC?"

Responses were analyzed in terms of whether there is a program specifically for future physics teachers; how many students the program has in it; whether there is recruitment, personnel activity, and/or funding associated with program; and what theories faculty express about future physics teachers.

\section{PATTERNS OF INSTITUTIONAL ENGAGEMENT}

Four broad patterns of physics teacher education activity emerged from this study ("inactive," "track," "active," and "priority"). In the sample of member institutions studied, these categories were about equally populated (about onefourth of the institutions fell into each category). A larger survey of institutions would be needed to determine if this distribution is representative, as well as whether the patterns of engagement correspond to institution type, physics department size, or other factors.

\section{A. "Inactive"}

"Inactive" institutions have no program specifically for future physics teachers. About one-fourth of the PhysTEC member institutions studied (7/27) fit this description. Faculty leaders at these institutions state that they value physics teacher education but perceive major barriers to educating physics teachers at their institution. For example, one faculty leader said that because his institution's school of education does not offer undergraduate teacher preparation, there is no route for physics majors to pursue an education emphasis. Another faculty leader's institution has no school of education at all. A third faculty leader perceives low demand for physics-specialized teachers in his state, where science teachers serve primarily in rural schools and teach all sciences. Another faculty leader reported that his physics department does not have physics teacher education as a priority, though it does have an active elementary teacher preparation program. In some cases these barriers may be as insurmountable as the faculty leaders perceive them to be. In other cases, there may be options for physics teacher preparation that the faculty members have not considered.

\section{B. "Track"}

A number of PhysTEC member institutions offer a track in the physics department specifically for future physics teachers but have very few students in that track (one or two in the last five years). About $30 \%$ of the member institutions studied $(8 / 27)$ fit this description. In several cases, faculty leaders put significant effort into creating this track, including major negotiation with the physics department, the school of education, and deans, as well as obtaining external funding to establish the track. Several described attractive tracks consisting of either a physics major with an education minor or education major with a physics minor, culminating in licensure after four or five years.

Faculty leaders expressed surprise and disappointment that so few students take advantage of the opportunity they created for students to pursue physics teaching. One faculty leader and his colleagues meet weekly to administer a program that does not yet have anyone in it. Another team of faculty leaders has recently produced a track that includes a physics major, math minor, courses in thermodynamics, quantum, and astronomy, and education courses instead of upper-division physics courses, "everything a high school teacher would need," and are waiting hopefully for participants; they wonder if there is a population of future physics teachers somewhere that they have not yet located, and are considering recruiting high school students. Several faculty leaders at "track" institutions offered theories as to why there are so few 
future physics teachers at their institution; these theories are summarized in Sec. V.

\section{C. "Active" and "Priority"}

"Active" institutions offer a track in the physics department specifically for future physics teachers with active recruitment, significant personnel activity, and/or funding to increase the number of students in the track. About one-fourth of the member institutions studied (7/27) fit this description. The distinction between institutions classified as "active" vs. "track" is that "active" institutions are succeeding in recruiting and graduating physics teachers, whereas "track" institutions have very few students entering through the door that has been created.

"Priority" institutions, meanwhile, have physics teacher education as a significant priority as evidenced by features such as the presence of a champion, faculty hires, funding for physics teacher education, and/or a multifaceted physics teacher education program. About $20 \%$ of the member institutions interviewed $(5 / 27)$ fit this description. The difference between "active" and "priority" institutions is a matter of degree and might not be reliably detected by the brief interviews conducted for this study. For this reason, these categories are reported together.

Some of the "active" and "priority" institutions are well known for their physics teacher production and have been promoted by PhysTEC as exemplars of physics teacher education. Others are less well known. One small liberal arts college in this study has had a secondary education concentration in physics for over 25 years and averages 3 graduates per year, about $1 / 3$ of their majors. At a certain state university in this study, there were zero physics teacher graduates for a decade or more until the school of education took the initiative to create a Master of Arts in Teaching program targeted to science majors; students in this program get a physics minor and a science teaching endorsement in five years, and 17 physics students have completed this program in the last six years. At a studied regional university, teacher education is integrated into the mission of every department, and science education faculty have joint appointments in the science education and their corresponding disciplinary department; through a variety of paths (one of which is a "physics teaching major"), they produce 2-5 physics teachers every year. Another regional university program also produces 2-5 physics teachers every year through a program based in the physics department, and perceives that the market in their region is eager for more well-qualified graduates; they are now targeting transfer students from community colleges.

\section{FACULTY THEORIES ABOUT LOW NUMBERS OF PHYSICS TEACHERS}

Faculty leaders expressed a number of theories as to why their institution's physics teacher education programs do not have more students in them. Some of these theories focus on structural barriers to increasing the number of physics teachers [2], including lack of certification pathways and specialized coursework for physics teaching. Other theories refer to attitudinal and cultural barriers [2], such as negative attitudes about teaching. Programs such as PhysTEC may support faculty leaders in overcoming or working around both of these types of barriers.

\section{A. Perceived structural barriers}

Some faculty members believe that their physics teacher education program is unsuccessful because it lacks a champion in physics who would take the lead on recruitment and program development. Others perceive that physics teacher education is not a priority in their department. The report of the Task Force on Teacher Education in Physics (T-TEP) found that every topproducing physics teacher education program had a champion, and that champions were rarely rewarded professionally at a level commensurate with their work [5]. Taken together, these findings indicate that institutional reward structures can be a significant barrier to faculty engagement in physics teacher education. PhysTEC should address this barrier in order to engage faculty and foster institutional change.

Some faculty leaders see barriers to physics teacher education in their department's undergraduate physics program. Many believe that there just aren't enough physics majors in their department to support a cohort of future physics teachers. Some feel that physics instruction in their department fails to inspire students to pursue physics or physics teaching. These barriers indicate a need to support departments in improving their undergraduate physics program, e.g., through workshops aligned with the report on Strategic Programs for Innovations in Undergraduate Physics (SPIN-UP) [6].

Some faculty theories point to the need for certification pathways that meet students' needs. Faculty leaders in some states perceive that their state's laws make it onerous for physics majors to get teaching certification; for example, a faculty leader in New Mexico reports that his state requires an undergraduate degree in secondary education for licensure. Some faculty leaders perceive that it is inappropriate for teachers in their region to specialize in physics, since they will most likely teach in a rural school where such specialization is a liability rather than an asset. Others say that students with an interest in teaching believe that a straight physics or engineering degree will be of more benefit to them than an education-focused degree, enabling them to be either practicing scientists or teachers in the future. Some faculty members perceive that students interested in physics teaching are deterred by upperdivision physics or math courses that their department requires. Some perceive that a larger STEM teacher education program (such as a UTeach replication) does not 
serve future physics teachers well enough, perhaps because they are a small fraction of the overall future STEM teacher population. The wide variety of challenges to developing well-designed certification pathways suggests a need for a wide variety of strategies. PhysTEC could support its member institutions by facilitating exchanges among member institutions, especially "active" and "priority" institutions, to share successful strategies.

Other faculty theories suggest an unmet need for highquality coursework specialized for future physics teachers. Faculty leaders report that students are turned off by courses in the school of education, which rarely feel relevant to physics teaching. Some faculty leaders are frustrated that the physics department cannot make room in the physics major for courses serving future physics teachers, or that the school of education cannot make room in an education major for courses serving future physics teachers. A related concern expressed by some faculty is lack of personnel with special expertise in physics teacher education. The T-TEP report states that courses focused on the learning and teaching of physics are essential for future physics teachers, and indeed such courses are a common feature of thriving physics teacher education programs [5]. PhysTEC can support its member institutions by helping more institutions offer specialized preparation.

\section{B. Attitudinal and cultural barriers}

Some faculty theories about low physics teacher production convey negative attitudes about teaching. Several faculty shared their perception that teachers are a disenfranchised population - underpaid, disrespected by their districts, and rewarded for seniority and test performance rather than content understanding or teaching skill; they sympathize with students who are not attracted to a teaching career. Some faculty members admit that other faculty members in their department are not in favor of physics teaching as a career, or that physics teacher education is not a priority in their department. A number of faculty leaders interviewed believe that students interested in physics teaching are weaker students, who leave the program because they don't succeed in upper-division

[1] Initial PhysTEC project partners included the American Physical Society (APS), the American Association of Physics Teachers (AAPT), and the American Institute of Physics (AIP). In 2009, PhysTEC became a project of APS and AAPT.

[2] P. D. Eckel and A. Kezar, Taking the reins: Institutional transformation in higher education (Praeger Publishers, Westport, CT, 2003).

[3] C. Henderson, A. Beach, and N. D. Finkelstein, J. Res. Sci. Tch. 48, 8 (2011).

[4] www.phystec.org/institutions retrieved 6/24/15 physics or math courses. A number of studies suggest that such perceptions about the teaching profession are overly negative. For example, top academic students tend to substantially underestimate teacher compensation [7]. Also, $90 \%$ of physics majors who go into teaching are satisfied or very satisfied with their job overall [8]. For PhysTEC to be successful in fostering institutional change, negative beliefs about the teaching profession need to be addressed.

Other faculty theories suggest cultural barriers to physics teacher production. Faculty leaders frequently report that it is difficult for physics and education colleagues to collaborate productively with each other; physics students who are turned off by education courses (or vice versa) may be reflecting the same antipathy. Lack of collaboration between physics departments and schools of education was also a finding of T-TEP [5]. Addressing this cultural barrier is critical to establishing certification pathways that meet students' needs.

\section{SUMMARY}

PhysTEC member institutions exhibit four broad patterns of institutional engagement with physics teacher education ("inactive," "track," "active," and "priority"). The widely differing levels of engagement suggest that different approaches may be needed to support member institutions in improving the education of future physics teachers.

Faculty theories about barriers to increasing the number of future physics teachers refer to both structural and attitudinal or cultural barriers. Identifying barriers that faculty experience is critical for PhysTEC to effectively assist faculty in negotiating these barriers and foster faculty leadership in physics teacher education.

\section{ACKNOWLEDGEMENTS}

This study was supported by the National Science Foundation under Grant No. 0808790.

[5] D. E. Meltzer, M. Plisch, and S. Vokos, Transforming the preparation of physics teachers: A call to action (American Physical Society, College Park, MD, 2012).

[6] Strategic Programs for Innovations in Undergraduate Physics: Project Report, Edited by R. C. Hilborn, R. H. Howes, K. S. Krane (American Association of Physics Teachers, College Park, MD, 2003).

[7] B. Auguste, P. Kihn, and M. Miller, Closing the talent gap: Attracting and retaining top-third graduates to careers in teaching (McKinsey, New York, 2010).

[8] C. L. Tsefaye and P. Mulvey, Physics bachelor's initial employment (American Institute of Physics, College Park, MD, 2012) 